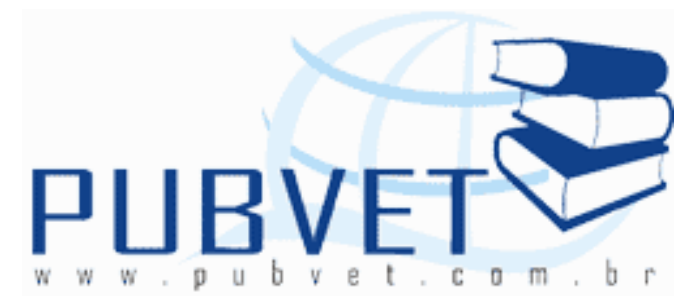

PUBVET, Publicações em Medicina Veterinária e Zootecnia.

\title{
Utilização de fisioterapia na síndrome do filhote nadador em felino doméstico
}

David Baruc Cruvinel Lima ${ }^{1}$, Hermínio José da Rocha Neto², Roseli Pizzigatti Klein $^{3}$

${ }^{1}$ Acadêmico de Medicina Veterinária - Centro de Ciências Agrárias (CCA) Universidade Federal do Piauí (UFPI).

${ }^{2}$ Médico Veterinário, Mestrando em Ciência Animal - Centro de Ciências Agrárias (CCA) - Universidade Federal do Piauí (UFPI).

${ }^{3}$ Médica Veterinária, Doutora em Medicina Veterinária - Centro de Ciências Agrárias (CCA) - Universidade Federal do Piauí (UFPI).

\section{Resumo}

A síndrome do filhote nadador é uma anormalidade do desenvolvimento, rara na espécie felina. O filhote acometido apresenta dificuldade de ambulação que pode afetar os membros anteriores e/ou posteriores. $O$ objetivo deste trabalho foi relatar o caso de um felino doméstico diagnosticado com síndrome do filhote nadador submetido a sessões de fisioterapia manual e estimulação locomotora em piso áspero. Foi atendido no Hospital Veterinário Universitário da Universidade Federal do Piauí um gato macho, sem raça definida, com 39 dias de vida, apresentando os membros pélvicos estendidos e deslocados lateralmente. Com base nos achados clínicos, o diagnóstico foi síndrome do filhote nadador e o tratamento consistiu de fisioterapia manual e estimulação 
do animal a caminhar em piso áspero. Ao final da terceira semana das sessões de fisioterapia o animal caminhava normalmente. A aplicação de fisioterapia manual e utilização de piso antiderrapante para estimulação locomotora representaram uma opção eficaz para o tratamento da síndrome do filhote nadador em felinos.

Palavras-chave: Gato; Síndrome; Locomoção; Fisioterapia.

\title{
Physiotherapy in swimmer puppy syndrome in cat
}

\begin{abstract}
The syndrome of the swimmer puppy is a developmental abnormality, rare in felines. The puppy affected has ambulation difficulty that can affect the anterior and/or posterior limbs. The objective of this study was to report the case of a domestic feline diagnosed with swimmer puppy syndrome subjected to manual physiotherapy sessions and locomotor stimulation in rough floor. It was attended in the University Veterinary Hospital of the Federal University of Piauí a male cat, undefined breed at 39 days of age presenting pelvic limbs outstretched and displaced laterally. Based on clinical findings, the diagnosis was syndrome of the swimmer puppy and the treatment consisted of manual physiotherapy and stimulation of the animal to walk on rough ground. At the end of the third week of the physiotherapy sessions the animal walked normally. The application of manual physiotherapy and use of non-slip floor for locomotor stimulation represented an effective option for treating swimmer puppy syndrome in cats.
\end{abstract}

Keywords: Cat; Syndrome; Locomotion; Physiotherapy.

\section{INTRODUÇÃO}

A síndrome do filhote nadador reconhecida primeiramente em filhotes caninos, sem predisposição sexual, é rara na espécie felina (MISTIERI et al.,2005; VERHOEVEN et al., 2006; BURGER et al., 2007). É uma anormalidade 

2013.

do desenvolvimento do filhote, também denominada de hipoplasia miofibrilar, de etiologia ainda contravertida. Tem sido relacionada a fatores genéticos e ambientais, atraso na mielinização pela falta de estímulo dos membros quando filhotes permanecem em superfície lisa e escorregadia, excesso ou falta de proteína na alimentação materna, além de uma alimentação subnutrida do filhote acometido (MELLO et al., 2008; YARDIMCI et al., 2009).

Os membros anteriores e/ou os posteriores podem ser acometidos. Se os membros pélvicos forem os afetados o animal apresenta movimentos rastejantes e o seu deslocamento assemelha-se a uma foca nadando, se acometer os membros anteriores, a perda da capacidade de sustentação do tronco pode levar o animal a rastejar sobre o esterno, o que pode provocar aplainamento dorsoventral do tórax (MISTIERI et al., 2005; PRATS et al., 2005).

O diagnóstico é baseado na anamnese e achados de exame clínico (HARKNESS \& McCORMICK, 1981; PRATS et al., 2005). Não existe tratamento específico, nem protocolo definido para esta síndrome. Os animais tratados precocemente apresentam uma maior chance de regressão das lesões e passsam a se desenvolver normalmente após a instituição do tratamento, o que permite uma melhor qualidade de vida ao paciente (MICHELETTI, 2009).

Diante do exposto, o objetivo deste trabalho foi relatar o caso de um felino doméstico diagnosticado com síndrome do filhote nadador submetido a sessões de fisioterapia manual e estimulação locomotora em piso áspero.

\section{DESCRIÇÃO DO CASO}

Um gato doméstico, macho, sem raça definida, com 39 dias de vida, pesando $350 \mathrm{~g}$ foi atendido no Hospital Veterinário da Universidade Federal do Piauí apresentando falta de apoio dos membros pélvicos que se mantinham estendidos e deslocados lateralmente (Figura 1). À inspeção observou-se que o paciente não conseguia sustentar os membros posteriores, assim como, não caminhava sobre piso liso ou áspero. O exame radiológico dos membros 

2013.

pélvicos nas posições látero-lateral e ventro-dorsal não revelou nenhuma alteração e o diagnóstico com base nos achados clínicos foi síndrome do filhote nadador. O animal permaneceu internado e o tratamento preconizado foi fisioterapia manual através de mobilização ativa dos membros posteriores com manobras de flexão e extensão articular (Figura 2). As sessões eram realizadas três vezes ao dia com duração de 20 minutos cada. Após cada sessão, o animal era estimulado a caminhar em piso áspero, visando um melhor apoio dos membros e consequente desenvoltura ao caminhar (Figura 3). Na terceira semana, a recuperação já era bastante significativa com o animal andando normalmente em qualquer tipo de piso, tanto áspero quanto liso e na quarta semana recebeu alta hospitalar.

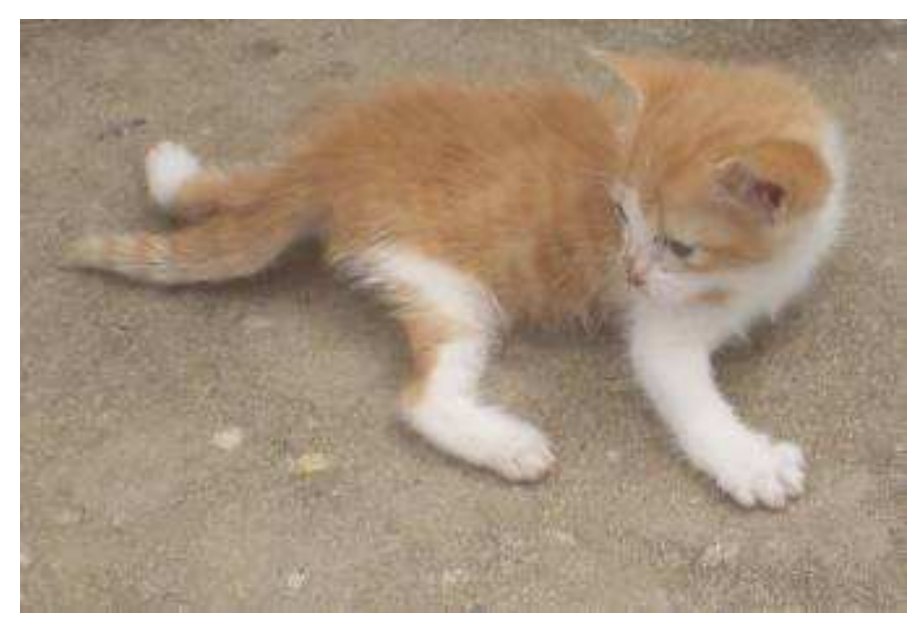

Figura 1: Gato doméstico apresentando membros pélvicos estendidos e deslocados lateralmente.

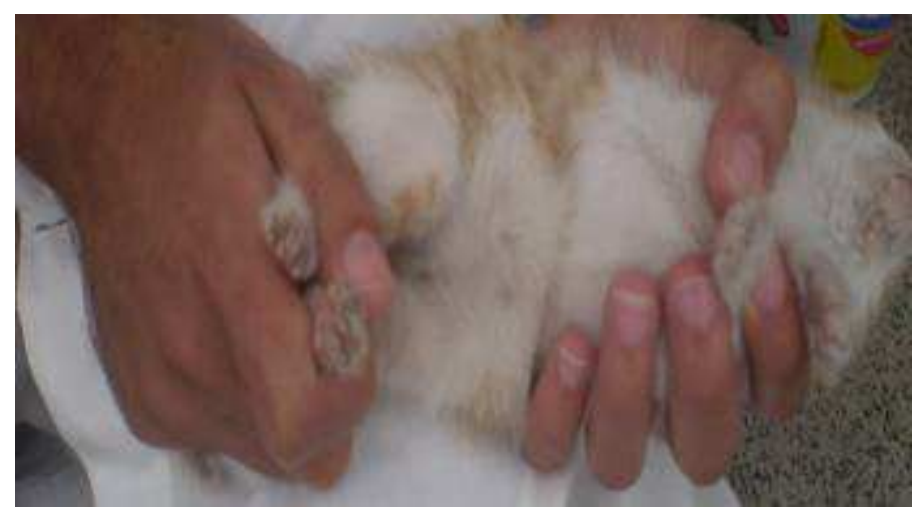

Figura 2: Sessão de fisioterapia manual em gato doméstico através de mobilização ativa dos membros posteriores com manobras de flexão e extensão articular. 


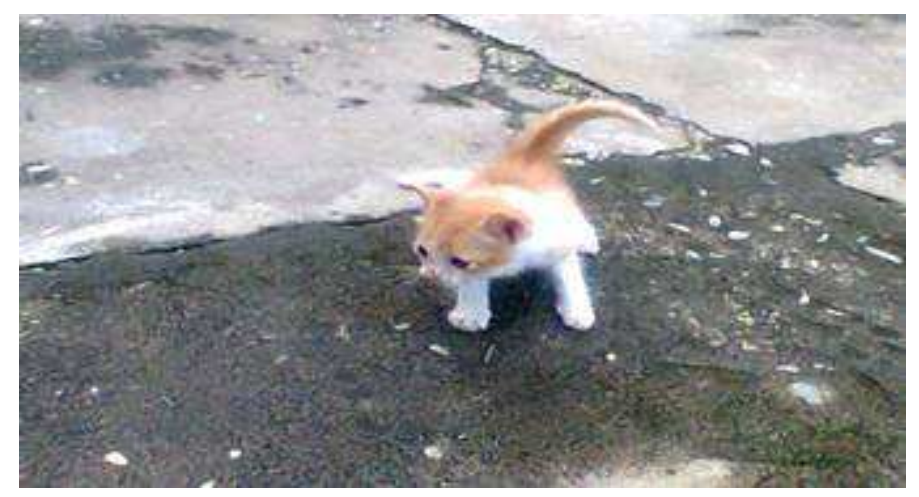

Figura 3: Gato doméstico após sessão de fisioterapia manual sendo estimulado a caminhar em piso áspero.

\section{DISCUSSÃo}

A partir da segunda a terceira semanas de idade, os sinais clínicos da síndrome do filhote nadador tornam-se evidentes, por ser este o período no qual deveria ser observada uma locomoção quadrupedal estável (MELLO et al., 2008). No caso descrito, o animal foi levado ao veterinário somente após cinco semanas de vida, no entanto, o resultado do tratamento não foi prejudicado.

O diagnóstico presuntivo da síndrome do filhote nadador foi realizado pela inspeção clínica e pela de radiografia torácica e pélvica conforme preconizado por Prats et al. (2005), porém, o exame radiográfico não evidenciou alterações.

Em gatos, dois trabalhos relatam o emprego da fisioterapia como protocolo terapêutico, porém, juntamente com a imobilização dos membros afetados com tipóia esparadrapada (MISTIERI et al., 2005) e bandagem (BURGER et al., 2007). Verhoeven et al. (2006) alertam que o procedimento da bandagem pode causar edema e isquemia, além de infecções de pele por urina e fezes.

A instituição de fisioterapia motora periodicamente e a estimulação do paciente para caminhar em piso áspero mostrou-se eficaz para a reabilitação locomotora do animal, corroborando com Verhoeven et al. (2006), que descreveram a utilização de fisioterapia como método eficaz de tratamento 
associado ao uso de bandagens, entretanto, no caso relatado não houve o inconveniente da bandagem, que pode gerar complicações a saúde do paciente.

O prognóstico de filhotes portadores da síndrome está relacionado ao diagnóstico precoce, acompanhamento constante, cuidados com a alimentação e implementação de exercícios supervisionados (SILVA et al., 2012). O paciente descrito foi supervisionado diariamente pelo veterinário durante as sessões de tratamento e nos demais cuidados clínicos.

\section{CONCLUSÃO}

Conclui-se que sessões de fisioterapia realizadas ou supervisionadas pelo médico veterinário, assim como a utilização de piso antiderrapante para estimulação locomotora do paciente representaram uma opção eficaz para o tratamento do felino doméstico com síndrome do filhote nadador permitindo uma total reabilitação da ambulação e a prevenção de complicações relacionadas a outros métodos terapêuticos, o que possibilitou uma melhor qualidade de vida ao paciente.

\section{REFERÊNCIAS}

BURGER, C. P.; SILVA, R. B.; CANOLA, J. C.; PADILHAFILHO, J. G.; OLIVEIRA, G. G. S.

Síndrome do filhote nadador em gato: relato de caso. Acta Scientiae Veterinariae, v. 35, n. supl. 4, p. s1393 - s1394, 2007.

HARKNESS, J.E.; McCORMICK, L.F. Swimming-puppy syndrome in a litter of German Shepherd pups.Vet. Med. Small An. Clin., v.76,n.6, p. 817-821, 1981.

MELLO, F. P. S.; NEUWALD, E. B.; ALIEVI, M. M. Síndrome do cão nadador - relato de 4 casos. Hífen, v. 32, n. 61, p. 51, 2008.

MICHELETTI, L. Síndrome do cão nadador: relato de caso. 2009. 29 f. Monografia - Centro Universitário FMU. São Paulo, 2009.

MISTIERI, M. L. A.; ISOLA, J. G. M. P.; NADRUZ, R. F.; COSSI, L. B.; SAITO, L. M. Síndrome do filhote nadador: relato de caso em gato. Revista Universidade Rural, v.25, suplemento, p.163-164, 2005. 
PRATS, A.; DUMON, C.; GARCIA, F.; MARTI, S.; COLL, V. Neonatologia e pediatria canina e felina. 1 ed. São Caetano do Sul: Interbook. 2005, 469p.

SILVA, T. O. B.; MUNIZ, I. M.; BÓBANY, D. M.; CARVALHO, R. M. M.; CASTRO, J. C. O. Síndrome do cão nadador: descrição de caso. Revista CFMV, v. 18, n. 56, p. 43-47, 2012.

VERHOEVEN, G.; ROOSTER, H.; RISSELADA, M.; WIEMER, P.; SCHEIRE, L.; VAN BREE, H. Swimmer syndrome in a devon rex kitten and an english bulldog puppy. Journal of Small Animal Practice, v. 47, n. 10, p. 615-619, 2006.

YARDIMCI, C.; ÖZAK, A.; NISBET, H. Ö.; SIRIN, Y. S. Swimming syndrome in two labrador puppies. Kafkas Univ Vet Fak Derg, v. 15, n. 4, p. 637-640, 2009. 